\title{
THE EMERGING ROLE OF MINDFULNESS RESEARCH IN THE WORKPLACE AND ITS CHALLENGES
}

\section{Vich, $M$.}

This paper focuses on the current state of art in mindfulness research on workplace and identifies some of the necessary steps and risks in the creation of mindful leadership theory. Mindfulness has the potential to effectively address three topical organizational challenges of growing demands on adaptability, prevailing issues of work-related stress and the necessity to raise the moral level in organizations. Current studies seem to suitably respond to the issues of work-related stress; however, the challenges of adaptability and morality so far lack appropriate empirical validation. Lack of empirical support is also noticeable in the case of mindful leadership theory as most studies still focus solely on individual leader development. However, it is important to start to discuss the suitable core variables of mindful leadership now as a clear differentiation from other leadership approaches like authentic leadership will be crucial for successful creation of mindful leadership theory. This paper also presents recommendations for entrepreneurs and managers willing to incorporate mindfulness into their organizational settings.

Keywords: mindfulness; mindfulness-based interventions (MBIs), mindful leadership; self-awareness; moral awareness; authentic leadership, ethical leadership.

JEL classification: M14, M53, O35

\section{Introduction}

After more than thirty years of existence, mindfulness-based interventions (MBIs) are highly demanded in developmental organizational programs today (Williams \& KabatZinn, 2011; Purser \& Milillo, 2015). Mindfulness is a suitable way for enhancing one's awareness and attention towards better ability to experience the present moment (Brown \& Ryan, 2003; Kabat-Zinn, 2003). The technological evolution of our society, advanced logistics and higher complexity are placing new demands on organizations. Organizations need to increase their adaptability (Heifetz, Grashow \& Linski, 2009), cope more smoothly with work-related stress (and other negative emotions) (Kabat-Zinn, 2013), and give more emphasis to the moral dimension of their functioning (Treviño \& Nelson, 2011). Mindfulness seems a suitable way to address these challenges more efficiently, through the enhancement of various kinds of awareness on the level of individuals (Weick \& Sutcliffe, 2006; Hunter \& Chaskalson, 2013).

Based on the presentation on the current state of art, this paper discusses the degree to which current mindfulness research really corresponds with contemporary organizational challenges. Studies suggest that current mindfulness research quite satisfactorily answers the issues related to work-related stress and other negative emotions (Hülsheger et al., 2013; Roche, Haar \& Luthans 2014; Shonin et al., 2014b). However, the current state of art completely lacks empirical support for addressing the required development of adaptability and morality. This paper also discusses the challenges of the possible emergence of mindful leadership theory. Although only one study has so far empirically examined the beneficial effects of a leader's mindfulness on his followers (Reb et al., 
2014), some of the individual level variables (e.g. work-related stress, job-engagement) could be reexamined in the case of the mutual relationship between leader and followers. Core variables of mindful leadership theory will also have to be clearly discriminated from the variables contained in existing leadership approaches in order to validate mindful leadership as a unique theory. This paper focuses firstly on the state of art of the individual effects of mindfulness on the workplace, secondly on the challenges of mindful leadership theory creation and the finally on recommendations for managers and entrepreneurs willing to implement MBIs into their organizations.

\section{Introduction to Mindfulness and Related Concepts}

This chapter presents some basic explanations of mindfulness and awareness, and the relationship between them. For the purpose of fuller understanding, the introduction also focuses on mindlessness and mind wandering, which to a certain degree, describe the state of mind which lacks mindfulness.

\subsection{Mindfulness and Awareness}

The most widespread and recognized branch of mindfulness and related MBIs is derived from Buddhist teachings (Carmody, 2014). One of the fundamental Buddhist texts related to mindfulness is Satipatthāna sutta (Jotika \& Dhamminda, 1986). The translation of Satipatthāna also serves as one of the basic tools for explaining mindfulness. According to Thera (1962), "sati" can be translated as "awareness", or "attentiveness" and patthāna as "placing near one's mind", or "keeping present". Satipatthāna can be therefore freely translated as "making awareness more present" or "being more aware of the present."

One of the most common "western" definitions of mindfulness explains it as "the awareness that emerges through paying attention on purpose, in the present moment, and nonjudgmentally to the unfolding of experience moment to moment" (Kabat-Zinn, 2003, p. 145). This definition suggests that mindfulness is about the achievement of a more clear experience of the present moment through the purposeful utilization of awareness and attention. Awareness can be defined as the ability to perceive, to feel, or to be conscious of events, objects, thoughts, emotions, or sensory patterns. It is also explained as the "background radar of consciousness," whose role is to continually monitor the inner and outer environments, while attention represents the process of focusing that awareness (Brown \& Ryan, 2003). Awareness, therefore, seems to precede attention, as "one may be aware of stimuli without them being at the center of attention" (Brown \& Ryan, 2003; 822). Yet more focused awareness seems to create more specific forms of awareness. Awareness which is more focused on oneself is called self-awareness (Crisp \& Turner, 2010); similarly the awareness, which is focused more on moral dimension of one's decisions / actions can be called moral awareness (Butterfield, Trevino \& Weaver, 2000). Attention and awareness are understood as the ordinary tools of the human mind, while mindfulness represents their enhancement towards current experience and present reality (Brown \& Ryan, 2003).

\subsection{Mindlessness and Mind Wandering}

Mindlessness is sometimes called as the opposite of mindfulness (Brown \& Ryan, 2003). Langer (1992) defines mindlessness as a "state of mind characterized by an overreliance 
on categories and distinctions drawn in the past and in which the individual is contextdependent and, as such, is oblivious to novel (or simply alternative) aspects of the situation" (p. 289). While dealing with tasks, mindless individuals can, for example, reduce attributes of a particular task to more available characteristics (mostly drawn from the past). This type of simplification is called "attribute substitution" and is one of the causes of unaware application of heuristics (Kahneman, 2003). Overreliance of heuristic decision-making therefore prevents the individual from perceiving the present situation as it is because of their strong attachment to past experience. Mindfulness is supposed to be an antidote to mindlessness and related decision-making errors, as it "weakens the tendency to simplify events into familiar events and strengthens the tendency to differentiate events into unfamiliar events" (Weick \& Sutcliffe, 2006, p. 518). Mindful individual can therefore better decode new information in a particular moment (Langer, 1992; Brown \& Ryan, 2003).

Mind wandering has been identified as a default mode of the human brain. It is a stimulus-independent through process (Mason et al., 2007), which usually manifests as a "rumination about future and past" (Goleman, 2013). Frequent mind wandering has been also recognized as contrary to experiencing happiness (Killingsworth \& Gilbert, 2010) and good physical condition (Mooneyham \& Schooler, 2013). Later findings suggest that issues related to mind wandering can be solved by the development of awareness (Killingsworth \& Gilbert, 2010) and mindfulness (Ottaviani \& Couyoumdjian, 2013). The goal is not to suppress the manifestation of mind wandering in any way, but just to be more aware of its functionality by the means of non-judgmental observation of the emerging thoughts and related emotions (Kabat-Zinn, 2013). In the other worlds, one can free one's attention by becoming more aware of one's own mind wandering episodes.

\section{Challenges of Contemporary Organizations}

The growing complexity and speed of our society is placing higher demands on the resilience and adaptability of organizations. Contrary to the technical challenges which can be solved by the existing know-how (usually based on previous experience), adaptive challenges require brand new methods, which must usually be created in a particular situation (Heifetz, Grashow \& Linski, 2009). Adaptive-type situations require individuals to be able to free their attention from the technical details in order to identify all components of the present issue (Dane, 2010) and overcome their mindlessness in a way of decoding the new information in the present situation (Weick \& Sutcliffe, 2006). Mindfulness seems to be a suitable answer for raising the adaptability of individuals as it is beneficial for both freeing the attention (Brown \& Ryan, 2003), more purposeful utilization of mind wandering (the mind wandering seems to be related to the firing of creative brain areas) (Goleman, 2013) and overcoming mindlessness (Langer, 1992). Leaders possessing highly adaptive decision-making are suggested to be the main components in organizational adaptability (Heifetz, Grashow \& Linski, 2009), and hence demand for mindful leaders seems to grow rapidly nowadays (Hunter \& Chaskalson; 2013; Langer, 2014).

Work-related stress and coping with emotions represent a more traditional, yet still front organizational challenge as the demands on the individual continue to escalate (Kabat-Zinn, 2013). Work-related stress was identified as the second most significant determinant of stress in the USA in 2014 (American Psychological Association, 2015) 
and as one of the major causes of work-related illnesses (39\%) in Great Britain in 2014 (Health and Safety Executive report, 2014). Based on summarization of several neural correlation studies, Chiesa, Seretti \& Jakobsen (2013) suggest that mindfulness practitioners can regulate their emotions either through top-down regulation (regulation through detached observation of incoming emotions and related thoughts) or bottom-up regulation (more direct control of the functionality of emotions-related areas of brain). Authors also conclude that more advanced practitioners could be able to develop both types of regulation. Recent research by Peters et al. (2015) also pointed to a significant positive relationship between mind wandering and aggression, suggesting that lowering rumination through mindfulness actually leads to reduction of anger. Development of mindfulness for the purpose of better coping with stress and other negative emotions seems to be especially crucial in leadership as some authors suggest a leader's emotional state to be easily distributed on followers (Boyatzis \& McKee, 2005). Such an emotional state seems to have an especially negative impact on the followers with higher degrees of agreeableness (kindness, willingness to cooperate, positive attitude) (Van Kleef et al., 2010).

Another rather traditional but escalating organizational challenge is morality and ethics in the workplace. Public interest in morality has grown after the revelation of the scandals of American companies like Enron or World Com (Schminke, Ambrose $\&$ Neubaun, 2005) and significantly more intensified after the debacle of the financial sector in 2008 (Treviño \& Nelson, 2011). The higher demand for moral organizations raised questions about the efficiency of moral decision-making on an individual level. Rest (1986) identified the four following steps of a moral decision-making process: moral awareness, moral judgment, establishment of moral intent and moral action. According to this model, development of moral awareness is the first essential step for successful development of all three of the following stages. Moral awareness can be defined as "person's recognition that his/her potential decision or action could affect the interests, welfare, or expectations of the self or others in a fashion that may conflict with one or more ethical standards" (p. 982). Individuals possessing high moral awareness can be more aware of the moral dimension of their everyday actions. Development of moral awareness can also provide response to the limited role of moral judgment. Limited moral judgment is based on findings which suggest that the moral decision-making process is significantly driven by affective and intuitive mechanisms (Haidt, 2001; Gibbs, 2014). Extending moral awareness to the examination of one's subtle psychical determinants of moral choice can be particularly helpful for making following moral choices more consciously. Mindfulness therefore seems to be complementary to the moral development for its enhancing effect to awareness and for developing the ability to cope with one's emotions.

\section{Role of Mindfulness in Authentic and Ethical Leadership}

The growing necessity to more explicitly incorporate morality into leadership has helped the emergence of the theories of authentic (Avolio \& Gardner, 2005) and ethical (Brown, Treviño \& Harrison, 2005) leadership. Both theories seem to be in close relationship with mindfulness nowadays. 


\subsection{Authentic Leadership and Mindfulness}

Authentic leadership is defined as a "pattern of leader behavior that draws upon and promotes both positive psychological capacities and a positive ethical climate, to foster greater self-awareness, an internalized moral perspective, balanced processing of information, and relational transparency on the part of leaders working with followers, fostering positive self-development" (Walumbwa et al., 2008, p. 94). Development of self-awareness and self-regulation (contained in an internalized moral perspective) is therefore essential for the establishment of an authentic relationship between the leader and follower (Luthans, 2003). Self-awareness is usually defined as the "psychological state in which people are aware of their traits, feelings and behavior (Crisp \& Turner, 2010, p.8)." Self-awareness helps both leaders and followers to gain a deeper insight into one's self, his/her strengths, weaknesses and values, while self-regulation helps to transform new insight into action (Avolio \& Gardner, 2005).

Authentic leadership is a growing field today (Dinh et al., 2014) and mindfulness seems to represent a very effective way for the development of the required self-awareness and self-regulation (Vago \& Silbersweig, 2012; Goleman, 2013b). Authentic leadership is apparently one of the first ways through which mindfulness strengthens its position in contemporary leadership.

\subsection{Ethical Leadership and Mindfulness}

Ethical leadership is the first leadership theory which has focused directly on the moral and ethical aspects of leadership. Ethical leadership is defined as "the demonstration of normatively appropriate conduct through personal actions and interpersonal relationships, and the promotion of such conduct to followers through two-way communication, reinforcement, and decision-making" (Brown, Treviño \& Harrison, 2005, p. 120). Ethical leaders are the main moral actors in organizations as they need to develop the transformational aspect to serve as moral role models for others and also a transactional aspect to promote the explicit communication about moral standards and to enforce their compliance (Brown, Treviño \& Harrison, 2005). Ethical leaders need to possess developed moral decision-making which is, according to Rest's model (1986), closely dependent upon the previously defined moral awareness. Mindfulness therefore seems to be supportive for more practical and efficient development of ethical leaders. Recent findings also suggest that development of mindfulness, in the case of followers, raises efficiency and ethical leadership as it is positively related to the amount of a follower's extra effort and helping (Eisenbeiss \& van Knippenberg, 2015).

\section{Mindfulness Research}

Measurement of mindfulness has become much more feasible since the development of self-reporting questionnaire methods; the most recognized of these methods is Mindful Attention Awareness Scale (MAAS) (Brown \& Ryan, 2003), which measures mindfulness like a personal trait (concretely by focusing on the aspects awareness and attentiveness). MAAS contains 15 questions designed to examine a respondent's mindfulness in regular daily situations and respondents choose one of the six options on a Likert scale $(1=$ Almost always, $6=$ Almost never $)$. Despite the criticisms for negative expression of 
the questions and self-reporting bias (questions are practically focused on a respondent's mindlessness) (Grossman, 2011), neglecting other important mindfulness aspects (e.g. non-judgmental, accepting attitude, or dis-identification) (Walach et al., 2006), and growing role of neuroimaging methods in the field (Chiesa, Sererretti \& Jakobsen, 2013; Tang, Hölzel \& Posner, 2015) MAAS still represents the most used tool for measuring mindfulness today. Dominance of MAAS is also no exception in the case of workplace and leadership related mindfulness studies. Most of the beneficial effects of mindfulness have been examined as a part of various Mindfulness Based Interventions (MBIs).

\subsection{Mindfulness-Based Interventions}

The most popular (and also first to be successfully applied) MBI today is Mindfulness Based Stress Reduction (MBSR) (Kabat-Zinn, 1982; Williams \& Kabat-Zinn, 2011; Kabat-Zinn, 2013). MBSR contains basic mindfulness exercises like body scanning, mindfulness of breath and simple hatha yoga postures (Kabat-Zinn, 2013). MBSR has been validated to be beneficial for the reduction of stress (Shapiro, Schwartz \& Bonner, 1998; Shapiro et al., 2003; Carlson et al, 2004; Carlson \& Garland, 2005), sleep disturbance (Shapiro et al., 2003; Carlson \& Garland, 2005), depression (Lengacher et al., 2009), and improvement of mood and perceived quality of life (Carlson et al., 2004; Carlson \& Garland, 2005; Lengacher et al., 2009).

MBSR has also served as an inspiration for other more specialized interventions like Mindfulness Based Cognitive Therapy (MCBT) (Teasdale, 1995), which has been proven to be beneficial for the reduction of depression and raising the quality of life of the patients with psychiatrically diagnosed diseases (Kuyken et al., 2008; Williams et al., 2008; Evans et al. 2008; Kim et al., 2008) or Mindfulness Based Relapse Prevention for Substance Use Disorders (MBRP) (Bowen et al., 2009). Some of the newer forms of MBIs, called also as the second-generation mindfulness interventions (SG-MBIs) follow the more traditional practice of mindfulness (Van Gordon, Shonin \& Griffiths, 2015). For example, similarly to original Buddhist teachings, Meditation Awareness Training (MAT) helps participants to develop mindfulness in accordance with the development of compassion and ethics (Shonin, Van Gordon \& Griffiths, 2014a). Contrary to MBSR, which focuses more on non-judgmental attitude, MAT gives stronger emphasis on active discrimination of the phenomena arising in the present experience (Van Gordon, Shonin \& Griffiths, 2015).

\subsection{Mindfulness-Based Interventions on Workplace}

Most of the mindfulness research set in a workplace environment has so far focused on the beneficial effects of mindfulness development on a particular individual. Hülsheger et al. (2013) examined the beneficial effects of mindfulness development on regular employees $(\mathrm{N}=219 ; \mathrm{N}=64)$ : mindfulness was positively related to job satisfaction and negatively related to emotional exhaustion. According to Leroy et al. (2013), the MBSR type mindfulness training (outcome measured by MAAS) of 76 participants ( $24 \%$ were managers) lead to an increase in job engagement (state of personal well-being, dedication and absorption in one's job). Two online studies suggested mindfulness to be positively related to job engagement, job performance (Andrews, Kacmar \& Kacmar, 2014) and job satisfaction (Dane \& Brummer, 2014) and negatively related to turnover 
intentions (possibility that an individual would leave the organization) (Andrews, Kacmar \& Kacmar, 2014; Dane \& Brummer, 2014). Roche, Haar \& Luthans (2014) examined the effect of level of mindfulness (MAAS) on psychological well-being in a sample of top $(\mathrm{N}=205)$, middle $(\mathrm{N}=183)$ and junior $(\mathrm{N}=202)$ managers, and also 107 entrepreneurs. Mindfulness was negatively related to anxiety, depression and had a negative effect in the case of managerial leaders, and to burnout in the case of entrepreneurs. Shonin et al. (2014b) applied MAT training to 152 middle managers. MAT lead to the increase of work-related well-being and employer-rated job performance and to the decrease of work-related stress.

Some recent studies also examined the effects of mindfulness in the mutual relationship between leader and followers. Two studies $(\mathrm{N}=96 ; \mathrm{N}=79)$ of Reb, Narayanan \& Chaturvedi (2014) have focused on the leadership effect: a leader's mindfulness (MAAS) was positively related to job performance and work-life balance of his/her subordinates. The study of Eisenbeiss \& Van Knippenberg (2015) has focused on the followership effect: follower mindfulness was positively related to the impact of ethical leadership (135 leader-follower dyads), resulting in an increase of followers offering extra effort and helping.

\section{Discussion}

Mindfulness at the workplace is still rather a pioneering discipline with lots of challenges ahead. This is particularly topical for mindful leadership. Discussion focuses on the presentation of the future directions and recommendations firstly for the researchers willing to extend the examination of mindfulness to the dimensions of adaptability and morality, secondly for the researchers willing to contribute to the mindful leadership theory creation and finally for the managers and entrepreneurs willing to implement MBIs in their organizational settings.

\subsection{Organizational Challenges and Mindfulness Research}

Most of the recent mindfulness research in the workplace has examined its beneficial effects on the level of the individual. Studies suggest mindfulness to be positively related to job satisfaction (Hülsheger et al., 2013; Dane \& Brummer, 2014), job engagement (Leroy et al., 2013), job performance (Shonin et al., 2014b; Andrews, Kacmar \& Kacmar, 2014) and work-related well-being (Shonin et al., 2014b; Roche, Haar \& Luthans 2014), and negatively related to emotional issues (Hülsheger et al., 2013; Roche, Haar \& Luthans 2014; Shonin et al., 2014b) and turnover intentions (Dane \& Brummer, 2014; Andrews, Kacmar \& Kacmar, 2014).

Recent studies therefore empirically support the positive effect of mindfulness in dealing with work-related stress and other emotional issues. Beneficial effects of mindfulness for the adaptability of individuals have been so far examined only indirectly through the work engagement, which contains certain creativity-related qualities like absorption (Leroy et al., 2013). However, for addressing adaptability more clearly, researchers should examine more directly the effect of mindfulness on adaptive decisionmaking. According to Hannah et al. (2013) advanced adaptive-decision making possesses heightened situational awareness, which is defined as "the perception of the elements in the environment within a volume of time and space, the comprehension of their meaning, 
and the projection of their status in the near future (Endsley, 1995, p. 36)" and can be measured by Situational Self-Awareness Scale (SSAS) (Govern, 2001). Considerable outcomes are also situational judgment, measurable by the Situational Judgment Test (SJT) (McDaniel et al., 2007) and individual adaptability, measurable by the Individual Adaptability Scale (I-ADAPT) (Ployhart, 2006).

The effects of mindfulness on the development of morality have also not been sufficiently empirically examined so far. Although one pioneering study suggested a positive effect of mindfulness on moral acting of individuals (Ruedy \& Schweitzer, 2010), none of the studies has yet examined the effect of mindfulness development in the case of individuals on their moral decision-making level. Researchers could focus on examination of the relationship between mindfulness and moral awareness. Moral awareness is usually measured by both qualitative (Butterfield, Treviño \& Weaver, 2000) and quantitative self-reporting methods (Reynolds, 2006). However, there still does not seem to be a validated quantitative scale, which would be clearly discriminated from similar scales like MAAS. Moral awareness could be possibly examined as a moderator between moral judgment, measured by defining issues test (DIT) (Rest et al., 1997) and intuitive moral foundations, measured by moral foundations questionnaire (MFQ) (Graham et al., 2011), as the relationship between moral intuition and moral judgment is subject to intense discussion (Haidt, 2001; Gibbs, 2014; Fehr, Yan \& Dang, 2015).

\subsection{Emergence of the Mindful Leadership Theory}

Mindful leadership, which can be explained as a mutual relationship between the leader and follower influenced by a leader's mindfulness, seems to be a possible next step of mindfulness research on the workplace. The positive effects of mindful leadership on job performance and work-life balance have already been examined in two studies by Reb, Narayanan \& Chaturvedi (2014). First of all, the researchers should examine variables which have been already examined on an individual level, particularly job satisfaction, job engagement, job performance, work-related well-being, work-related stress anxiety, depression, burnout and turnover intentions. Secondly researchers need to take into account clear differentiation from other already existing leadership approaches. More specifically, researchers need to choose the variables which will not overlap with core variables of other leadership approaches. Authentic leadership represents a considerable challenge in this way as its core variable, self-awareness (Walumbwa et al., 2008), closely relates to awareness, which is inseparable from mindfulness (Brown \& Ryan, 2003; KabatZinn, 2013). Therefore authentic leadership seems to serve as an important doorway for mindfulness into the leadership on one hand and a real challenge for the creation of sovereign mindful leadership theory on the other hand. However, ethical leadership does not seem to be such an obstacle for the creation of mindful leadership as ethical leadership focuses more on moral outcomes like honestly or trueness and does not contain any variables related to awareness or attentiveness (Brown, Treviño \& Harrison, 2005; Fehr, Yan \& Dang, 2015). Moral awareness could therefore be incorporated into mindful leadership theory, which could also partially respond to the growing critics of some of work-related MBIs for lacking the moral foundation (inseparable from original Buddhist approach to mindfulness) (Purser \& Milillo, 2015). Finally, researchers could consider development of the new scales for more specific measuring mindfulness at the workplace. 
Some authors have already attempted to create the adapted version of MAAS (Dane \& Brummer, 2014). However, development of a whole new scale based on the report of a leader's colleagues (followers or employers) would be a considerable contribution to the research.

\subsection{Challenges of Practical Application of MBIs in Organization Settings}

The popularity of MBIs is growing so fast that some authors exhibit big concerns about the authenticity of some of the proposed programs (Grossman, 2011; Shonin et al., 2014a; Purser \& Milillo, 2015). Implementing MBIs into organizational settings is more feasible than ever before. On the other hand, leaders, managers and entrepreneurs need to learn to differentiate between appropriate programs in order the get the required results. The first recommendation is to choose a validated program, which is usually represented by an advanced researcher and practitioner. Implementation of MBI into organizational settings does not require the presence of the leading author of a particular program, but it definitely requires a certified facilitator. And even the certification is not a guarantee of quality in some cases. It is always important to thoroughly examine the biography of a particular trainer, especially his/her own dedication to the practices taught. Managers and entrepreneurs willing to implement particular MBI should also be clear about their motivation of implementing such a program. Some effects of mindfulness (job performance, job engagement) indicate its possible desirable outcomes for an organization's profit. On the other hand, truly dedicated practitioners base their motivation more on helping themselves and others to experience more well-being and freedom in life. The right intention is an important part of a truly mindful practice and especially teaching as it helps the facilitator to truly support the participants in the training group. Focusing on well-being of people in an organization rather than on profit can be helpful for smooth implementation of particular MBI. For similar reasons, it is important to understand that participation in these programs needs to always be voluntary.

\section{Conclusion}

This paper examined the relationship of mindfulness to three actual organizational challenges of growing demands on adaptability, work-related stress and necessity of moral development. Current research of mindfulness within the workplace satisfactorily corresponds to the problems of work-related stress; however, research in the fields of adaptability and moral development is very limited. Researchers need to extend their examination into these two dimensions in order to support the evidence for highly required beneficial effects which mindfulness seems to represent. It is also necessary to shift from the examination of the individual effects to the effects in working relationships. That is the necessary step towards creation of mindful leadership theory. Development of the research in these ways can help mindfulness to be better understood among entrepreneurs and managers and therefore more properly applied. 


\section{References}

Andrews, M. C., Kacmar, K. M., \& Kacmar, C. (2014). The mediational effect of regulatory focus on the relationships between mindfulness and job satisfaction and turnover intentions. Career Development International, 19(5), 494-507.

American Psychological Association. (2015). Stress in America: Paying with our health. Retrieved May 29, 2015 from http://www.apa.org/news/press/releases/stress/2014/stressreport.pdf.

Avolio, B. J., \& Gardner, W. L. (2005). Authentic leadership development: Getting to the root of positive forms of leadership. Leadership Quarterly, 2005(16), 315-338.

Bowen, S. et al. (2009). Mindfulness-based relapse prevention for substance use disorders: A pilot efficacy trial. Substance Abuse, 30(4), 295-305.

Brown, K. W., \& Ryan, R. M. (2003). The benefits of being present: Mindfulness and its role in psychological well-being. Journal of Personality and Social Psychology, 84(4), 822-848.

Brown, M. E., Treviño, L. K., \& Harrison, D. A. (2005). Ethical leadership: A social learning perspective for construct development and testing. Organizational Behavior and Human Decision Processes, 97(2), 117-134.

Butterfield, K. D., Treviño, L. K., \& Weaver, G. R. (2000). Moral awareness in business organizations: Influences of issue-related and social context factors. Human Relations, 53(7), 981- 1018.

Carlson, L. E., \& Garland, S. N. (2005). Impact of mindfulness-based stress reduction (mbsr) on sleep, mood, stress and fatigue symptoms in cancer outpatients. International Journal of Behavioral Medicine, 12(4), 278-285.

Carlson, L. E. et al. (2004). Mindfulness-based stress reduction in relation to quality of life, mood, symptoms of stress and levels of cortisol, dehydroepiandrosterone sulfate (dheas) and melatonin in breast and prostate cancer outpatients. Psychoneuroendocrinology, 29(4), 448-474.

Carmody, J. (2014). Eastern and Western Approaches to Mindfulness: Similarities, Differences, and Clinical Implications. The Wiley Blackwell Handbook of Mindfulness, 48-57.

Chiesa, A., Serretti, A., \& Jakobsen, J. C. (2013). Mindfulness: Top-down or bottom- up emotion regulation strategy? Clinical Psychology Review, 33(1), 82-96.

Crisp, R. J., \& Turner, R. N. (2010). Essential Social Psychology: 2nd Edition. New York: Sage.

Dane, E. (2010). Reconsidering the trade-off between expertise and flexibility: a cognitive entrenchment perspective. Academy of Management Review, 35(4), 579-603.

Dane, E., \& Brummel, B. J. (2014). Examining workplace mindfulness and its relations to job performance and turnover intention. Human Relations, 67(1), 105-128.

Dinh, J. E. et al. (2014). Leadership theory and research in the new millennium: Current theoretical trends and changing perspectives. Leadership Quarterly, 25(1), 36-62.

Eisenbeiss, S. A., \& van Knippenberg, D. (2015). On ethical leadership impact: The role of follower mindfulness and moral emotions. Journal of Organizational Behavior, 36(2), 182-195.

Endsley, M. R. (1995). Toward a theory of situation awareness in dynamic systems. Human Factors, 37(1), 32-64.

Fehr, R., Yam, K. C. S., \& Dang, C. (2015). Moralized leadership: The construction and consequences of ethical leader perceptions. Academy of Management Review, 40(2), 182-209. 
Gibbs, J. C. (2014). Moral Development and Reality: Beyond Theories of Kohlberg, Hoffman, and Haidt: Third Edition. New York: Oxford University Press.

Goleman, D. (2013). Focus: The Hidden Driver of Excellence. New York: Harper.

Govern, J. M., \& Marsch, L. A. (2001). Development and validation of the situational self-awareness scale. Consciousness and Cognition, 10(3), 366-378.

Graham, J. et al. (2011). Mapping the moral domain. Journal of Personality and Social Psychology, 101(2), 366-385.

Grandy, G., \& Holton, J. (2013). Leadership development needs assessment in healthcare: a collaborative approach. Leadership and Organization Development Journal, 34(5), 427-445.

Grossman, P. (2011). Defining mindfulness by how poorly I think I pay attention during everyday awareness and other intractable problems for psychology's (re)invention of mindfulness: Comment on Brown et al. (2011). Psychological Assessment, 23(4), 1034-1040.

Haidt, J. (2012). Richterous Mind: Why Good People are Divided by Politics and Religion. New York: Pantheon Books.

Hannah, S. T. et al. (2013). The psychological and neurological bases of leader self-complexity and effects on adaptive decision-making. Journal of Applied Psychology, 98(3), 393-411.

Health and Executive. (2014) Stress-related and psychological disorders in Great Britain. Retrieved May 28, 2015 from http://www.hse.gov.uk/statistics/causdis/stress/.

Heifetz, R., Grashow, A., \& Linsky, M. (2009). Leadership in a (permanent) crisis. Harvard Business Review, 2009(July-august), 1-9.

Hülsheger, U. R. et al. (2013). Benefits of mindfulness at work: The role of mindfulness in emotion regulation, emotional exhaustion, and job satisfaction. Journal of Applied Psychology, 98(2), 310-325.

Hunter, J., \& Chaskalson, M. (2013). Making the Mindful Leader. The Wiley-Blackwell Handbook of the Psychology of Leadership, Change, and Organizational Development, 195-219.

Kabat-Zinn, J. (1982). An outpatient program in behavioral medicine for chronic pain patients based on the practice of mindfulness meditation: Theoretical considerations and preliminary results. General Hospital Psychiatry, 4(1), 33-47.

Kabat-Zinn, J. (2003). Mindfulness-based interventions in context: Past, present, and future. Clinical Psychology-Science and Practice, 10(2), 144 - 156.

Kabat-Zinn, J. (2013). Full Catastrophe Living (Revised Edition), Using the Wisdom of Your Body and Mind to Face Stress, Pain, and IIIness. Bantam, New York.

Kahneman, D. (2003). Maps of bounded rationality: Psychology of behavioral economics. Americal Economic Review, 93(5), 449-1475.

Killingsworth, M. A., \& Gilbert, D. T. (2010). A wandering mind is an unhappy mind. Science, 330(6006), 932-932.

Kleef, G. A. et al. (2010). On angry leaders and agreeable followers: How leader's emotions and follower's personalities shape motivation and team performance. Psychological Science, 21(12), 1827-1834.

Kuyken, W. et al. (2008). Mindfulness-based cognitive therapy to prevent relapse in recurrent depression. Journal of Consulting and Clinical Psychology, 76(6), 966-978.

Langer, E., Blank, A., \& Chanowitz, B. (1978). The mindlessness of ostensibly thoughtful action: The role of "placebic" information in interpersonal interaction. Journal of Personality and Social Psychology, 36(6), 635-642. 
Langer, E. J. (2014). Mindfulness in the age of complexity. Harvard Business Review, 92(3), 68-78.

Langer, E. J., \& Rodin, J. (1976). The effects of choice and enhanced personal responsibility for the aged: A field experiment in an institutional setting. Journal of Personality and Social Psychology, 34(2), 191-198.

Lengacher, C. A. et al. (2009). Randomized controlled trial of mindfulness-based stress reduction (mbsr) for survivors of breast cancer. Psycho-Oncology, 18(2), 1261-1272.

Leroy, H. et al. (2013). Mindfulness, authentic functioning, and work engagement: A growth modeling approach. Journal of Vocational Behavior, 82(3), 238-247.

Luthans, F., \& Avolio, B. (2003). Authentic Leadership: A Positive Developmental Approach. In Cameron, K., \& Dutton, J. (Eds.) Positive Organizational Scholarship. San Francisco: Barrett-Koehler.

Mason, M. F. et al. (2007). Wandering minds: the default network and stimulus-independent thought. Science, 315(5810), 393-395.

McDaniel, M. A. et al. (2007). Situational judgment tests, response instructions, and validity: a meta-analysis. Personnel psychology, 60(1), 63-91.

Mooneyham, B. W., \& Schooler, J. W. (2013). The costs and benefits of mind-wandering: a review. Canadian Journal of Experimental Psychology, 67, 11-18.

Peters, J. R. et al. (2015). Anger rumination as a mediator of the relationship between mindfulness and aggression: The utility of a multidimensional mindfulness model. Journal Of Clinical Psychology, 71(9)m 871-884

Ployhart, R. E., \& Bliese, P. D. (2006). Advances in Human Performance and Cognitive Engineering Research, chapter Individual Adaptability (I-ADAPT) Theory: Conceptualizing the Antecedents, Consequences, and Measurement of Individual Differences in Adaptability. Amsterdam: Elsevier.

Purser, R. E., \& Milillo, J. (2015). Mindfulness revisited: A Buddhist-based conceptualization. Journal of Management Inquiry, 24(1), 3-24.

Reb, J., Narayanan, J., \& Chaturvedi, S. (2014). Leading mindfully: Two studies on the influence of supervisor trait mindfulness on employee well-being and performance. Mindfulness, 2014(5), 36-45.

Rest, J. et al. (1997). Alchemy and beyond: Indexing the defining issues test. Journal of Educational Psychology, 89(3), 498-507.

Rest, J. R. (1986). Moral development: Advances in research and theory. Praeger, New York.

Reynolds, S. J. (2006). Moral awareness and ethical predispositions: Investigating the role of individual differences in the recognition of moral issues. Journal of Applied Psychology, 91(1), 233-243.

Reynolds, S. J. (2008). Moral attentiveness: who pays attention to the moral aspects of life? Journal of Applied Psychology, 93(5), 1027-1041.

Roche, M., Haar, J. M., \& Luthans, F. (2014). The role of mindfulness and psychological capital on the well-being of leaders. Journal of Occupational Health Psychology, 19(4), 476-489.

Ruedy, N. E., \& Schweitzer, M. E. (2010). In the moment: The effect of mindfulness on ethical decision making. Journal of Business Ethics, 2010(95), 73-87.

Schminke, M., Ambrose, M. L., \& Neubaum, D. O. (2005). The effect of leader moral development on ethical climate and employee attitudes. Organizational Behavior and Human Decision Processes, 87(2), 135-151. 
Shamir, B. \& Eilamb, G. (2005). "what's your story?" a life-stories approach to authentic leadership development. Leadership Quarterly, 16(3), 395-417.

Shapiro, S. L. et al. (2003). The efficacy of mindfulness-based stress reduction in the treatment of sleep disturbance in women with breast cancer an exploratory study. Journal of Psychosomatic Research, 54(1), 85-91.

Shapiro, S. L., Schwartz, G. E., \& Bonner, G. (1998). Effects of mindfulness-based stress reduction on medical and premedical students. Journal of Behavioral Medicine, 21(6), 581-599.

Shonin, E. et al. (2014a). Meditation awareness training (mat) for work-related wellbeing and job performance: A randomized controlled trial. International Journal of Mental Health and Addiction, 12, 806-823.

Shonin, E., Gordon, W. V., \& Griffiths, M. D. (2014b). The emerging role of Buddhism in clinical psychology: Toward effective integration. Psychology of Religion and Spirituality, 6(2), 123-137.

Tang, Y., Hölzel, B. K., \& Posner, M. I. (2015). The neuroscience of mindfulness meditation. Nature Reviews Neuroscience, 16(4), 213-225.

Teasdale, J. D., Segal, Z., \& Williams, M. J. (1995). How does cognitive therapy prevent relapse and why should attentional control (mindfulness) training help? Behavior Research and Therapy, 33(1), 25-39.

Thera, N. (1962). The Heart of Buddhist Meditation. Ryder and Co., London.

Vago, D. R., \& Silbersweig, D. A. (2012). Self-awareness, self-regulation, and self-transcendence (s-art): a framework for understanding the neurobiological mechanisms of mindfulness. Frontiers in Human Neuroscience, 6(296), 1-30.

Walach et al. (2006). Measuring mindfulness-the freiburg mindfulness inventory (fmi). Personality and Individual Differences, 40(8), 1543-1555.

Walumbwa et al. (2008). Authentic leadership: Development and validation of a theory-based measure. Journal of Management, 34(1), 89-126.

Weick, K. E., \& Sutcliffe, K. M. (2006). Mindfulness and the quality of organizational attention. Organization Science, 17(4), 514-524.

Williams, J. G., \& Kabat-Zinn, J. (2011). Mindfulness: diverse perspectives on its meaning, origins, and multiple applications at the intersection of science and dharma. Contemporary Buddhism, 12(1), 1-18.

\section{Author}

\section{Ing. Marek Vich}

Ph.D. Candidate, Organizational Psychologist and Mentor

Department of Managerial Psychology and Sociology

Faculty of Business Administration

University of Economics, Prague

W. Churchill Sq. 4, 13067 Prague 3, Czech Republic

marek.vich@malp.cz

This paper has been supported by Internal Grant Agency VŠE (project no. F3/71/2015). 